\title{
Resistivity imaging across the source region of the 2004 Mid-Niigata Prefecture earthquake (M6.8), central Japan
}

\author{
Makoto Uyeshima $^{1}$, Yasuo Ogawa ${ }^{2}$, Yoshimori Honkura ${ }^{3}$, Shigeru Koyama ${ }^{1}$, Naoto Ujihara ${ }^{3}$, Toru Mogi ${ }^{4}$, Yusuke Yamaya ${ }^{4}$, \\ Makoto Harada $^{5}$, Satoru Yamaguchi ${ }^{6}$, Ichiro Shiozaki ${ }^{7}$, Tatsuya Noguchi ${ }^{7}$, Yoshihiro Kuwaba ${ }^{7}$, Yoshikazu Tanaka ${ }^{7}$, \\ Yuji Mochido $^{7}$, Noriko Manabe ${ }^{7}$, Masanori Nishihara ${ }^{7}$, Mamoru Saka ${ }^{1}$, and Masato Serizawa ${ }^{1}$

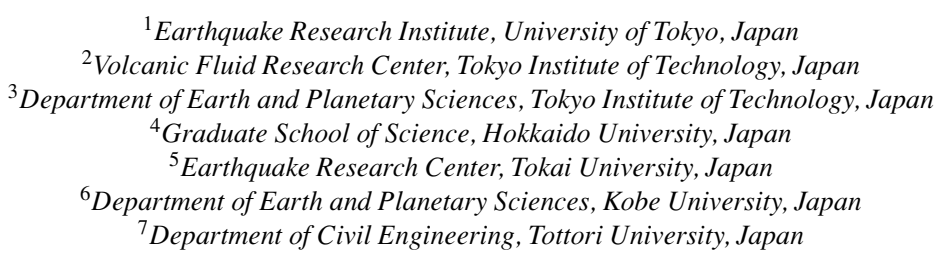

(Received February 25, 2005; Revised April 20, 2005; Accepted April 21, 2005)

\begin{abstract}
Across the source region of the 2004 Mid-Niigata Prefecture earthquake, wideband magnetotelluric (MT) survey was performed just after the onset of the mainshock. Owing to the temporal stop of the DC powered railways around the area together with intense geomagnetic activity, we obtain MT records with excellent quality for both short and long period data, as long as 10,000 s. Two dimensional regional strike is evaluated with the aid of the Groom-Bailey tensor decomposition together with induction vector analysis. As a result, $\mathrm{N} 15^{\circ} \mathrm{W}$ is determined for the strike. This strike is oblique to the local geological trend and also to the strike of the main shock source fault together with aftershock distribution of $\mathrm{N} 35^{\circ} \mathrm{E}$. Two dimensional resistivity structure is determined with the aid of an ABIC inversion code, where static shift is considered and estimated. Characteristics of the structure are as follows. (1) About $10 \mathrm{~km}$ thick sedimentary layer exists on the top. (2) A conductive body exists in the lower crust beneath the source region. The mainshock occurred at the boundary of the conductive sedimentary layer and a resistive basement beneath it and aftershocks occurred in the sedimentary layer. From geological studies, it is reported that the sedimentary layer was formed in the extensional rift-structure from Miocene to Pleistocene and has been thickened by compressional tectonic regime in the late Quaternary. Interstitial fluids or clay minerals, which reduce the sedimentary layer resistivity, control the reactivation of the normal fault as the mainshock thrust fault and aftershock activity. The second conductive body probably indicates existence of fluids in the depths as well. Such a conductive layer in the lower crust was also revealed by previous MT experiments along the Niigata-Kobe Tectonic Zone and probably plays a main role in concentration of strain rate along the zone.
\end{abstract}

Key words: Resistivity structure, magnetotelluric sounding, 2004 Mid-Niigata Prefecture earthquake, water, clay minerals, Niigata-Kobe Tectonic Zone.

\section{Introduction}

The 2004 Mid-Niigata Prefecture Earthquake of M6.8 occurred at 17:56 on 23, Oct., 2004 in the backarc area of the central main Japan island. Focal mechanism of this earthquake is the reverse fault type with a strike of approximately $\mathrm{N} 35^{\circ} \mathrm{E}$ and a dip of approximately $60^{\circ}$ according to the moment tensor by the National Research Institute for Earth Science and Disaster Prevention (NIED). The focal area is located in the eastern margin of the MiocenePleistocene thick sedimentary basin, which is characterized by the NNE-SSW trended anticline-syncline system forming Uonuma and Higashi-Kubiki Hills (Yanagisawa et al., 1986). Such folding structure suggests that compressional stress in the WNW-ESE direction has been prevailing in the late Quaternary and the focal mechanism of the present

Copy right(c) The Society of Geomagnetism and Earth, Planetary and Space Sciences (SGEPSS); The Seismological Society of Japan; The Volcanological Society of Japan; The Geodetic Society of Japan; The Japanese Society for Planetary Sciences; TERRAPUB mainshock is consistent with these recent geologic settings. The sedimentary basin was initially formed in a rift structure by stretching activity from Miocene, coincedent with the Japan Sea opening. At that time, a normal fault system was formed at the eastern edge of the sedimentary basin. This fault system has been reactivated as a reverse fault system (the Muikamachi and Obirou Faults in Fig. 1) with change of the tectonic regime from extension to compression (Sato, 1994; Hirata et al., 2005a). The Obirou Fault detected on the surface to the north of Koide is regarded as a surface extension of the source fault of the present mainshock. To the east of the fault system, Mesozoic basement rocks are exposed to the surface, which forms the high and steep Echigo range.

A recent research by using Japanese nationwide GPS array (GEONET) datasets revealed detailed characteristics of the relative crustal movement between the Northeastern Japan (NEJ) and the Southwestern Japan (SWJ) together with the effects of subduction of the Pacific Plate 


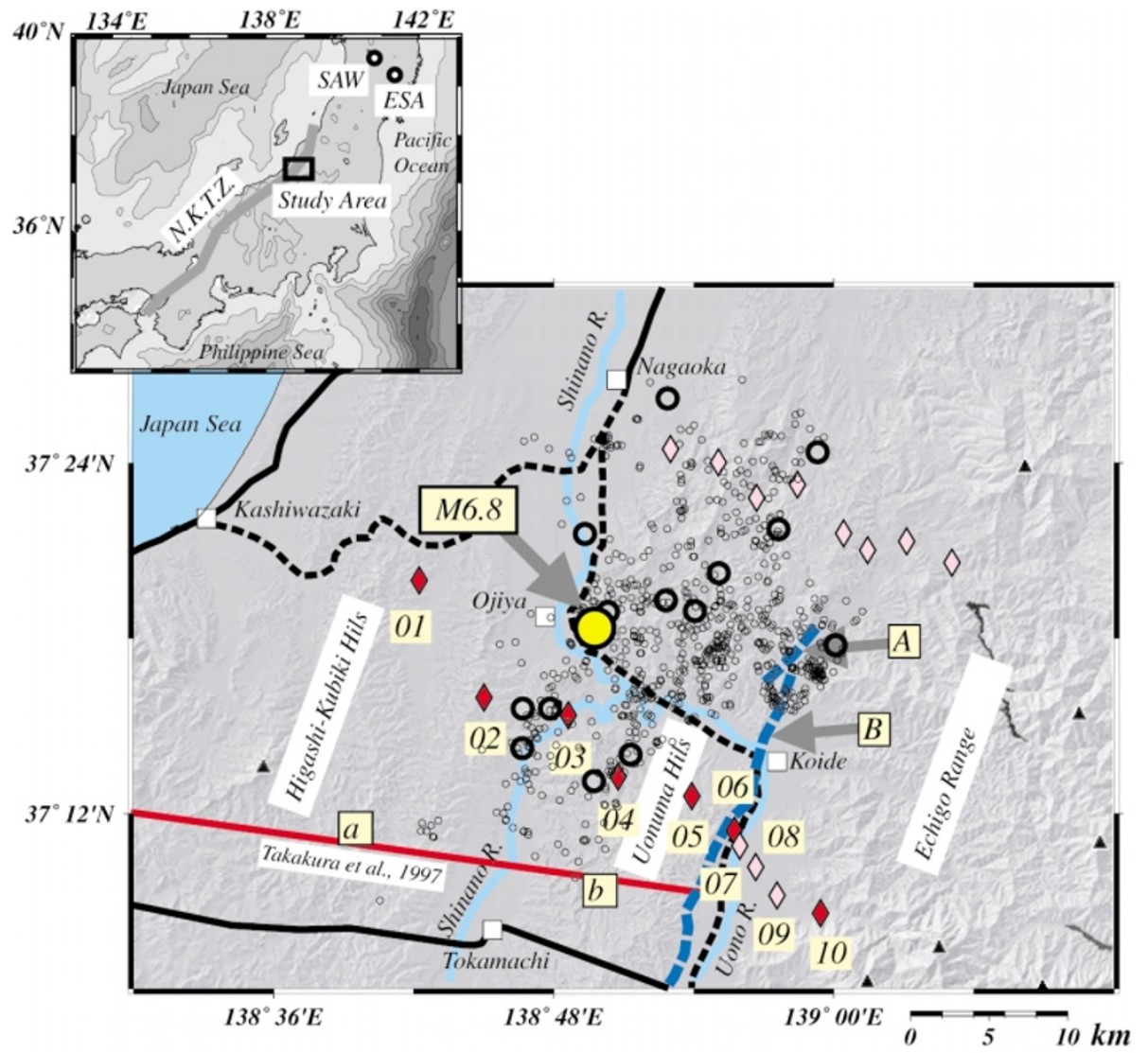

Fig. 1. Site map together with index map at the top left. In the index map, remote reference sites ESA and SAW are shown. Niigata-Kobe Tectonic Zone (N.K.T.Z., Sagiya et al., 2000) is shown by a grey line. In the site map, red and pink diamonds indicate MT sites for Nov., 2004 and Dec. 2004 surveys, respectively. Also plotted are the mainshock with large yellow circle, main aftershocks (>M5.5) with thick open circles and the other aftershocks with small circles, which are all relocated by Sakai et al. (2005). Also shown are DC-powered electric railways. Solid and broken lines in black respectively indicate railways in operation and not in operation during the Nov. 2004 survey. A red line across the Higashi-Kubiki and Uonuma Hills indicates the MT survey line by Takakura et al. (1997). Squares indicate sites of pilot drilling, a: Higashi Kubiki, b: Shinsui. Bold blue broken lines indicate the Obirou Fault (marked by A) and the Muikamachi Fault (marked by B).

and the Philippine Plate beneath both NEJ and SWJ (Heki and Miyazaki, 2001). After removing the short-term elastic response due to subduction, they found from long-term velocity field that NEJ and SWJ respectively acts almost rigidly and large strain rate is restricted in rather narrow zones. Niigata-Kobe Tectonic Zone (N.K.T.Z. in Fig. 1, Sagiya et al., 2000) forms a motional boundary between NEJ and SWJ running along the back-arc side of the central Japan, where the present earthquake focal area is located.

In order to determine an electrical structure related to the mainshock and aftershock activities and also to elucidate the reason for strain accumulation in the narrow zone that caused the disastrous earthquake, we performed a wideband magnetotelluric (MT) survey in the epicentral area just after the onset of the mainshock. One reason to conduct such a survey urgently was that DC-powered railways surrounding the area were not in operation (black broken lines in Fig. 1) due to the problems of landslides and aftershock ground motions. Another reason was to detect the electromagnetic (EM) signals related to nearby aftershocks (e.g. Matsushima et al., 2002) and to examine its generation mechanism. The results of EM signals to aftershocks will be reported in the future.

\section{Field Operations}

A location map of MT sites is shown in Fig. 1. The field operations were completed in two surveys. The first survey was performed along the survey line just to the south of the mainshock from 5th to 19th, Nov., 2004. We set azimuth of the survey line as $\mathrm{N} 55^{\circ} \mathrm{W}-\mathrm{S} 55^{\circ} \mathrm{E}$ by considering trend of surface geology, mechanism of the mainshock and aftershock activities (Sakai et al., 2005; Hirata et al., 2005b). In the survey, in addition to non functioning of the DC railways (shown as black broken lines in Fig. 1), a significant magnetic storm occurred from 7 th to 10 th, Nov. The second survey was performed mainly along the survey line in the northern part of the epicentral area from 1st to 11th, Dec., 2004. Since quality of records at site 06 in the first survey was not good, we put additional 3 sites on the southern line between site 06 and 10 in the second campaign. In addition to that only moderate geomagnetic activities occurred from 5th to 6th, Dec., all the DC railways except that between Nagaoka and Koide were recovered from 29th, Nov. Then quality of records along the northern line in the second survey was not good and the data still wait further processing. Thus, in this paper, we only report results from the southern line.

Five component MT instruments MTU5 of Phoenix Geo- 


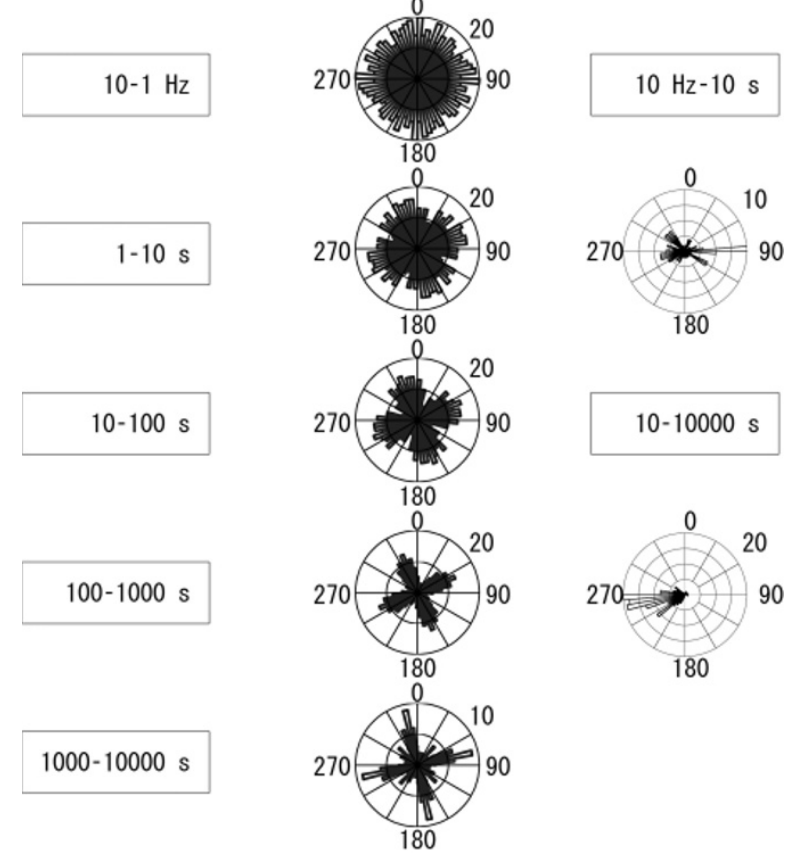

Fig. 2. In the left-hand column, are shown rose diagrams which indicate cumulative circular frequency distribution of the regional strikes of all the sites for respective one decade period ranges. Rose diagrams for the azimuth of the in-phase induction vectors of all the sites for respective period ranges are shown in the right-hand column. Number shown between $0^{\circ}$ and $90^{\circ}$ indicates number of cases corresponding to the outermost circle.

physics Ltd. were deployed at sites $01-05$ and $08-10$, and two component electric fields at sites 06 and 07 were measured by MT2E of the same company. We obtained records intermittently in 2 bands at sampling rates of 2560 and 320 $\mathrm{Hz}$ and continuously at $24 \mathrm{~Hz}$ sampling rate.

\section{Analysis}

We first estimated the impedance tensor in the frequency domain. In order to avoid bias due to existence of local magnetic noise, we applied the remote reference technique (Gamble et al., 1979). As remote references, we used the horizontal magnetic fields at Esashi station (operated by Geographical Survey Institute, ESA in Fig. 1) for datasets in November and those at Sawauchi station (operated by Nittetsu Mining Consultants Co. Ltd., SAW in Fig. 1) for datasets in December. For the sites 06 and 07, where only electric fields were measured, we used the horizontal magnetic fields at nearby station with good quality (site 10 for site 06 and site 09 for site 07 ) In estimating the impedance tensor, robust processing techniques were used to minimize bad influences from outliers in the electric field records. We first selected records with significant geomagnetic activities and applied selective weighting based on multiple coherency between electric and magnetic fields. Owing to the significant magnetic storm and absence of leakage current from nearby DC railways, quality of impedances for the first survey was excellent up to periods as long as $10^{4}$ s except those at site 06 . As for the second survey, quality of the impedances depends on distance between respective sites and the DC railway line. We could not use site 07 records at all.
In evaluation of the two dimensional (2-D) strike, we encountered a following problem. Although the surface geologic trend and strike of the mainshock source fault together with aftershock distribution are in $\mathrm{N} 35^{\circ} \mathrm{E}-\mathrm{S} 35^{\circ} \mathrm{W}$, which is consistent with the survey line, site and frequency dependent Groom-Bailey (GB) decomposition (Groom and Bailey, 1989) revealed that the regional 2-D strike for periods longer than $10 \mathrm{~s}$ is in $\mathrm{N} 15^{\circ} \mathrm{W}-\mathrm{S} 15^{\circ} \mathrm{E}$ with $90^{\circ}$ ambiguity, as shown in Fig. 2. Since the in-phase induction vector at all the stations points to around $\mathrm{S} 75^{\circ} \mathrm{W}$ in the same period range as is also shown in Fig. 2, we determined $\mathrm{N} 15^{\circ} \mathrm{W}-$ $\mathrm{S} 15^{\circ} \mathrm{E}$ as a $2-\mathrm{D}$ regional strike. Since area with significantly low Bouguer gravity anomaly is distributed to the WSW of the survey line (Komazawa, 2004), this inconsistency between regional geologic trend and the present two dimensional regional strike may be controlled by existence of conductive thick sediments there. Thus, we applied GB decomposition again by fixing the regional strike as $\mathrm{N} 15^{\circ} \mathrm{W}-$ $\mathrm{S} 15^{\circ} \mathrm{E}$ to yield regional 2-D responses which would be inverted. The TE and TM responses were plotted in Fig. 3.

\section{Two Dimensional Resistivity Structure}

After projecting all the sites on a line in the $\mathrm{S} 75^{\circ} \mathrm{W}-\mathrm{N} 75^{\circ} \mathrm{E}$ direction, we inverted TE and TM-mode impedances by using an inversion code of Ogawa and Uchida (1996), where static shifts in both modes are also considered and estimated. We set error floor as $10 \%$. The final model with 2.47 RMS is shown in Fig. 4. Fits of the model impedances to the observed ones are shown in Fig. 3. In Fig. 4, relocated hypocenter distribution of the mainshock and aftershocks (Sakai et al., 2005) are also plotted. Since the azimuth of the 2-D transect is oblique to the original survey line which is consistent with trend of aftershock spatial distribution, we first projected hypocenters within width of $\pm 10 \mathrm{~km}$ to the original survey line in $\mathrm{N} 55^{\circ} \mathrm{W}-\mathrm{S} 55^{\circ} \mathrm{E}$, then re-projected them to the 2-D transect in $\mathrm{S} 75^{\circ} \mathrm{W}-\mathrm{N} 75^{\circ} \mathrm{E}$.

An almost $10 \mathrm{~km}$ thick conductive layer $(<10 \Omega \mathrm{m})$ is detected just beneath the Uonuma Hills. Thickness of the conductive body gradually decreases in the east direction and rapidly decreases to the west of site 01 . The conductive layer extends to the east of the Uonuma Hills beyond the Uono river. The mainshock occurred just on the boundary between the thick conductive layer and resistive layer beneath it. Aftershocks are distributed in the conductive portion. Beneath the resistive layer, a moderately conductive layer of several tens of $\Omega \mathrm{m}$ is detected in the lower crust from the center of the profile to the east.

\section{Discussion}

The resistivity image in this study first indicates existence of thick conductive layer from the surface to a depth of 10 $\mathrm{km}$. Just to the south of our present survey line, MT survey across the Higashi-Kubiki and Uonuma Hills was performed by Takakura et al. (1997) (red line in Fig. 1). They determined a 2-D resistivity structure by using TM-mode impedances. Their model also shows a conductive layer as thick as about $8 \mathrm{~km}$ at the center of their profile near the pilot drilling site Higashi-Kubiki (a in Fig. 1, Takakura, 1995; Japan National Oil Corp., 1991). Depth of the drill 

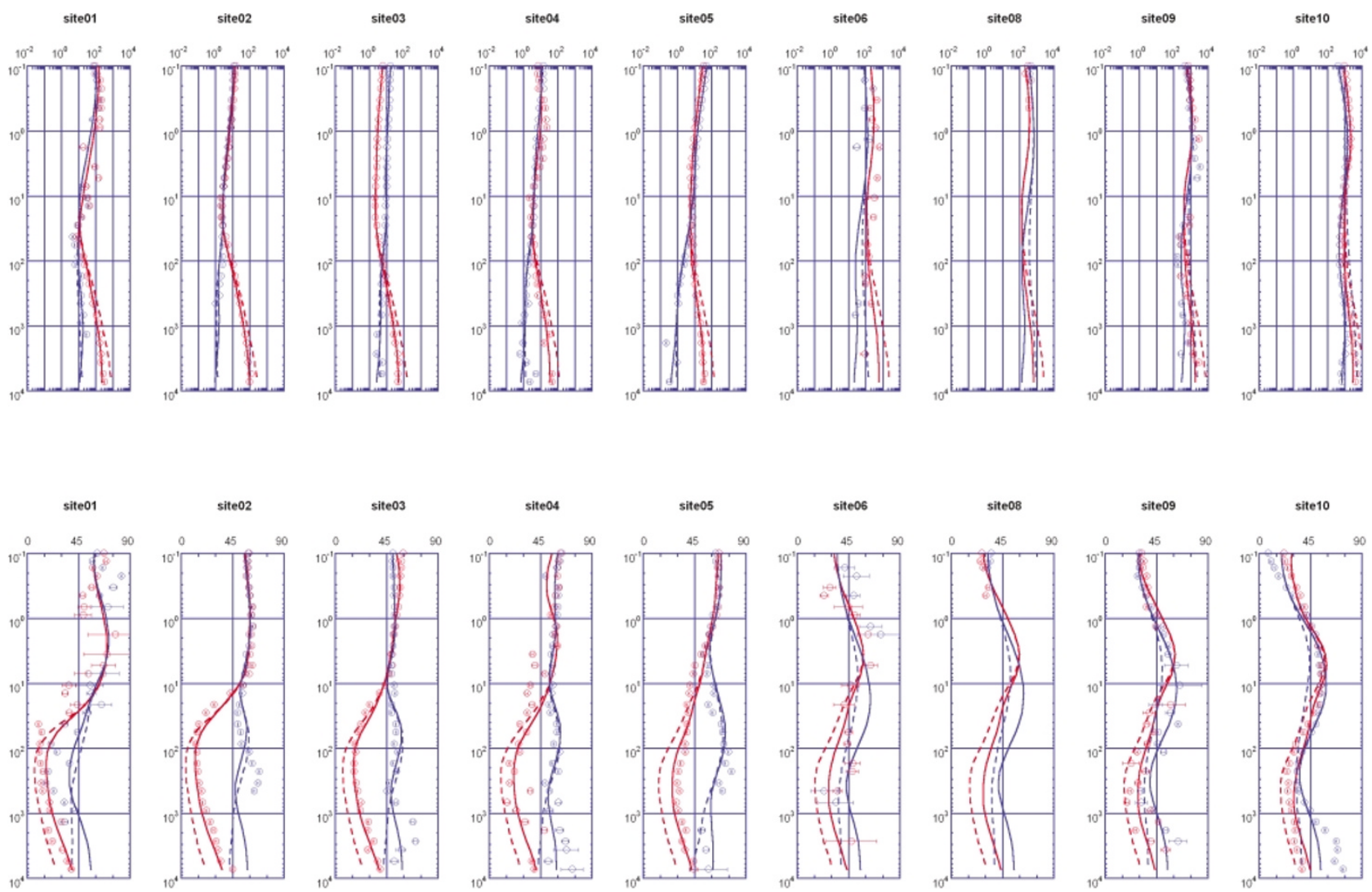

Fig. 3. Comparison between observed 2-D MT-responses (circles with error bars) and synthetic responses (solid curves) calculated from the final model in Fig. 4. Broken curves are synthetic responses computed from a test model for examining sensitivities of the responses to existence of the deeper conductor. Apparent resistivity in $\Omega \mathrm{m}$ and phase in degree are shown in the upper and lower rows. Red and blue color respectively indicates TE- and TM-mode impedances. Vertical axis is period in s.

hole was $6 \mathrm{~km}$ and it could not penetrate the thick sedimentary layers from middle Miocene to Pleistocene. By comparing their model with the logging records, they attributed the low resistivity to existence of conductive clay minerals such as smectite down to a $5 \mathrm{~km}$ depth. Existence of interstitial fluids in sedimentary layers is another reason for the low resistivity since the porosity is about $30 \%$ near the surface and several per cent even at bottom of the borehole. The latter effect becomes dominant at depths deeper than 5 $\mathrm{km}$ since conductive clay minerals are broken due to high temperature $\left(212^{\circ} \mathrm{C}\right.$ at a $6 \mathrm{~km}$ depth). Thus our thick conductive layer just beneath the surface can also be explained by existence of clay minerals and interstitial fluids in sedimentary layers. The present resistivity structure has a similarity to the seismic tomography result (Kato et al., 2005) in that the lower resistivity corresponds to the lower velocity or the higher $V_{p} / V_{s}$ ratio. This is because existence of clay minerals and interstitial fluids reduces $P$-wave velocity and enhances the $V_{p} / V_{s}$ ratio. The mainshock occurred just under the boundary between such weak sedimentary layers and basement rocks beneath it. Aftershocks are induced by the loading of the shear stress released into the sedimentary layers filled with interstitial fluids or clay minerals. As was mentioned in the introduction, the source fault of the mainshock is considered to be a reactivated reverse fault with a dip angle of approximately $60^{\circ}$ from the horizontal maximum compressional axis. Since such a fault is classified as an unfavorably oriented fault (Sibson, 1990), Kato et al.
(2005) argued that the high pore fluid pressure or the low frictional coefficient within the fault zone is necessary to reactivate the inverted normal fault. The present resistivity structure also supports this view. Further, joint interpretation of seismic and electric structures will reveal the physical property of the focal area with better constraints.

In the former 2-D resistivity model by Takakura et al., 1997, thickness of the surface conductive layer significantly decreases to about $2 \mathrm{~km}$ in the eastern part of their profile beneath the Uonuma Hills and highly resistive body ( $>300$ $\Omega \mathrm{m})$ appears beneath it. Their TM-mode impedances in the area are completely different from ours, too. Our TM-mode apparent resistivity at sites $01-06$ almost monotonically decreases from $10 \mathrm{~s}$ to $10^{4} \mathrm{~s}$ while phase keeps higher than $45^{\circ}$ as shown in Fig. 3, whereas their apparent resistivity rapidly and monotonically increases from several seconds to $10^{3} \mathrm{~s}$ and phase abruptly decreases in a period range from $1 \mathrm{~s}$ to $10 \mathrm{~s}$. It may be possible that resistivity structure has drastically changed after the mainshock and a series of large aftershocks. However, we cannot rule out the possibility that their records in the Uonuma Hills were significantly contaminated by the leakage current from the nearby DCrailways along the Uono river to show the near-field feature (e.g. Goldstein and Strangway, 1975). Although their resistivity depth profile on the Higashi-Kubiki Hills were consistent with resistivity logging data at five boreholes including the Higashi-Kubiki borehole, a discrepancy was detected from the comparison of their structure and resistivity log- 


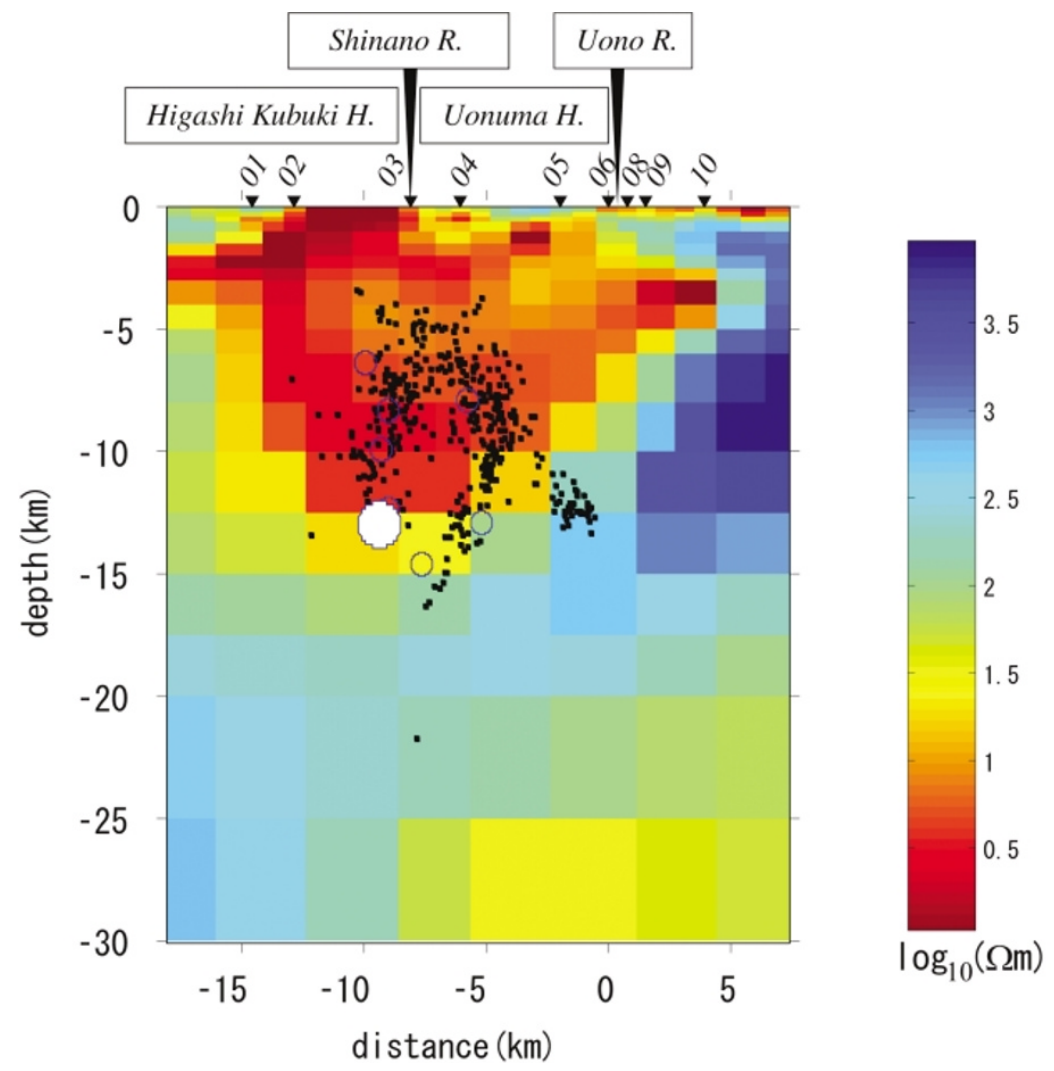

Fig. 4. Two dimensional resistivity model. The cross section is shown along with the relocated aftershocks by Sakai et al. (2005). Large white circle, small open circles and dots respectively indicate M6.8 mainshock, main aftershocks $(M>5.5)$ and the other aftershocks.

ging data at the Shinsui borehole site in the Uonuma Hills (b in Fig. 3). The resistivity logging shows low resistivity from 1 to several tens $\Omega \mathrm{m}$ down to the bottom of the borehole at a depth of $3 \mathrm{~km}$. This seems to support the latter view.

Furthermore, we found a conductive body of about several tens $\Omega \mathrm{m}$ in the lower crust from the center of the profile to the east. In order to examine a sensitivity of the present MT responses to existence of the conductive body, we made a test model where the resistivity values at greater than 15 $\mathrm{km}$ depths were set to be uniformly $500 \Omega \mathrm{m}$ and the upper structure remained to be same as the final model in Fig. 4. The synthetic responses from the test model are plotted by broken lines in Fig. 3. RMS for the test model is 4.63, whereas 2.47 for the final model, and deviation from the observation is significant especially in TE-mode phase at all the sites and in TM-mode phase at sites in the eastern part of the profile. Thus the present MT responses are well sensitive to the deeper conductive body in spite of the significant screening effect due to existence of the near surface thick conductive sedimentary layer. Since temperature at a $30 \mathrm{~km}$ depth is estimated as about $1,000^{\circ} \mathrm{C}$ by simple extraporation from the borehole temperature, resistivity of the dry crustal rocks ranges from several hundreds to $10^{4} \Omega \mathrm{m}$ at that depth (e.g. Kariya and Shankland, 1983). Then additional conductive phase is necessary to explain the low resistivity. Existence of interstitial water is one candidate to enhance the conductivity. In many focal areas in Japan are obtained similar structures that low resistivity exists beneath the hypocenters (e.g. Ogawa et al., 2001; Mitsuhata et al., 2001; Kasaya et al., 2002). Existence of localized weak zone due to interstitial fluids concentrates strain in elastic layer above it (Iio et al., 2002; Hyodo and Hirahara, 2003). If such a weak structure continues in rather narrow zone, surface deformation concentrates along the zone. In Central Japan to the west of the present target area, similar conductive bodies at depths from the lower crust to the upper mantle are detected along the Niigata Kobe Tectonic Zone (Goto et al., 2005; Ogawa et al., 2002; Ogawa and Honkura, 2004).

\section{Conclusions}

We performed a wide-band MT survey across the source area of the 2004 Mid-Niigata Prefecture earthquake just after the onset of the mainshock. Owing to the tentative cessation of the nearby DC-railways and intensive geomagnetic storm, we could obtain excellent electromagnetic records and successfully determined the resistivity structure down to the lower crust. Characteristics of the structure are as follows. (1) About $10 \mathrm{~km}$ thick sedimentary layer exists on the top. (2) A conductive body exists in the lower crust beneath the source region. The mainshock occurred at the boundary of the conductive sedimentary layer and a resistive basement beneath it and aftershocks occurred in the sedimentary layer. The structure benefited us to draw deep inferences on the mechanisms of the disastrous earthquake. In the future we will also analyze the records from the northern transect and investigate the structural change along the trend of the focal area. We also plan to examine the inconsistency between our 2-D strike and the geological and seismological 
trend with the aid of the 3-D analysis (Siripunvaraporn et al., 2005a,b).

Acknowledgments. We would like to express sincere gratitude for local people who kindly permitted us to use their properties to make measurements in spite of difficult situations just after or during the disaster. We also thank staffs in city offices who kindly negotiated with local people for the sake of our survey. The Geographical Survey Institute and the Nittetsu Mining Consultants Co. Ltd. kindly let us use their continuous geomagnetic records respectively at ESA and SAW as remote references. Valuable comments from Dr. T. Harinarayana and Dr. Y. Nishida help to improve contents and English expressions of this paper. This work was supported by the Special Coordination Funds for the Promotion of Science and Technology offered by the Ministry of Education, Culture, Sports, Science and Technology of Japan (MEXT) under the title of Urgent Research for the 2004 Mid-Niigata Prefecture Earthquake, the Grant-in-Aid for Special Purposes (16800054), and a grant offered under the Earthquake Prediction Research program of MEXT.

\section{References}

Gamble, T. D., J. Clarke, and W. M. Goubau, Magnetotellurics with a remote magnetic reference, Geophysics, 44, 53-68, 1979.

Goldstein, M. A. and D. W. Strangway, Audio-frequency magnetotellurics with a grounded electric dipole source, Geophysics, 40, 669-683, 1975.

Goto, T., Y. Wada, N. Oshiman, and N. Sumitomo, Resistivity structure of a seismic gap along the Atotsugawa fault, Phys. Earth Planet. Inter., 148, 55-72, 2005.

Groom, R. W. and R. C. Bailey, Decomposition of magnetotelluric impedance tensors in the presence of local three-dimensional galvanic distortions, J. Geophys. Res., 94, 1913-1925, 1989.

Heki, K. and S. Miyazaki, Plate convergence and long-term crustal deformation in Central Japan, Geophys. Res. Lett., 28, 2313-2316, 2001.

Hirata, N., H. Sato, and Research Group for the Urgent Aftershock of the Earthquake Research Institute, University of Tokyo, The 2004 MidNiigata Prefecture Earthquake-Source faults estimated by the subsurface structure and aftershocks, Kagaku, 75, 149-151, 2005a (in Japanese).

Hirata, N., H. Sato, S. Sakai, A. Kato, and E. Kurashimo, Fault system of the 2004 Mid Niigata Prefecture Earthquake and its aftershocks, Landslides, 2, doi:10.1007/s10346-005-0050-8, 2005 b.

Hyodo, M. and K. Hirahara, A viscoelastic model of interseismic strain concentration in Niigata-Kobe Tectonic Zone of central Japan, Earth Planets Space, 55, 667-675, 2003.

Iio, Y., T. Sagiya, Y. Kobayashi, and I. Shiozaki, Water-weakened lower crust and its role in the concentrated deformation in the Japanese Islands, Earth Planet. Sci. Lett., 203, 245-253, 2002.

Japan National Oil Corp., Research report on the pilot drilling at "HigashiKubiki" for prospecting petroleum and natural gas in Japan, 1991 (in Japanese).

Kariya, K. A. and T. J. Shankland, Electrical conductivity of dry lower crustal rocks, Geophysics, 48, 52-61, 1983.

Kasaya, T., N. Oshiman, N. Sumitomo, M. Uyeshima, Y. Iio, and D. Uehara, Resistivity structure around the hypocentral area of the 1984 Western Nagano Prefecture earthquake in central Japan, Earth Planets Space, 54, 107-118, 2002.

Kato, A., E. Kurashimo, N. Hirata, S. Sakai, T. Iwasaki, and T. Kanazawa, Imaging the source region of the 2004 mid-Niigata prefecture earthquake and the evolution of a seismogenic thrust-related fold, Geophys.
Res. Lett., doi:10.1029/2005GL022366, 2005.

Komazawa, M., High-resolution Bouguer gravity anomaly map around the source region of the 2004 mid-Niigata prefecture earthquake on the web: http://unit.aist.go.jp/igg/rg/geophysmap-rg/grav/niigata_grav_fig.html, Institute of Geology and Geoinformation, AIST, 2004.

Matsushima, M., Y. Honkura, N. Oshiman, S. Baris, M. K. Tuncer, S. B. Tank, C. Celik, F. Takahashi, M. Nakanishi, R. Yoshimura, R. Pektas, T. Komut, E. Tolak, A. Ito, Y. Lio, and A. M. Isikara, Seismoelectromagnetic effect associated with the Izmit earthquake and its aftershocks, Bull. Seis. Soc. Am., 92, 350-360, 2002.

Mitsuhata, Y., Y. Ogawa Y., M. Mishina, T. Kono, T. Yokokura, and T. Uchida, Electromagnetic heterogeneity of the seismogenic region of 1962 M6.5 Northern Miyagi Earthquake, northeastern Japan, Geophys. Res. Lett., 28, 4371-4374, 2001.

Ogawa, Y. and Y. Honkura, Mid-crustal electrical conductors and their correlations to seismicity and deformation at Itoigawa-Shizuoka Tectonic Line, Central Japan, Earth Planets Space, 56, 1285-1291, 2004.

Ogawa, Y. and T. Uchida, A two-dimensional magnetotelluric inversion assuming Gaussian static shift, Geophys. J. Int., 126, 69-76, 1996.

Ogawa, Y., M. Mishina, T. Goto, H. Satoh, N. Oshiman, T. Kasaya, Y. Takahashi, T. Nisitani, S. Sakanaka, M. Uyeshima, Y. Takahashi, Y. Honkura, and M. Matsushima, Magnetotelluric imaging of fluids in intraplate earthquakes zones, NE Japan back arc, Geophys. Res. Lett., 28, 3741-3744, 2001.

Ogawa, Y., S. Takakura, and Y. Honkura, Resistivity structure across Itoigawa-Shizuoka tectonic line and its implications for concentrated deformation, Earth Planets Space, 54, 1115-1120, 2002.

Sagiya, T., S. Miyazaki, and T. Tada, Continuous GPS array and presentday crustal deformation of Japan, Pure Appl. Geophys., 157, 23032322, 2000.

Sakai. S., N. Hirata, A. Kato, E. Kurashimo, T. Iwasaki, and T. Kanazawa, Multi-fault system of the 2004 Mid-Niigata Prefecture Earthquake and its aftershocks, Earth Planet Space, 57, this issue, 417-422, 2005.

Sato, H., The relationship between late Cenozoic tectonic events and stress field and basin development in northeastern Japan, J. Geophys. Res., 99, 22261-22274, 1994.

Sibson, R. H., Rupture nucleation on unfavorably oriented faults, Bull. Seis. Soc. Am., 80, 1580-1604, 1990.

Siripunvaraporn, W., G. Egbert, Y. Lenbury, and M. Uyeshima, Threedimensional magnetotelluric inversion: data-space method, Phys. Earth Planet. Int., 150, 3-14, 2005a.

Siripunvaraporn, W., G. Egbert, and M. Uyeshima, Interpretation of 2-D magnetotelluric data with 3-D inversion, Geophys. J. Int., 160, 804-814, 2005 b.

Takakura, S., Resistivity of Neogene rocks in the Niigata and the Akita oil fields, Japan, BUTSURI-TANSA, 48, 161-175, 1995 (in Japanese with English abstract).

Takakura, S., K. Nakagami, Y. Mitsuhata, and R. Murayama, Petroleum geological interpretation of resistivity structure based on magnetotelluric and deep well data in the Higashi-Kubiki area, Niigata, Japan, $J$. Jpn. Assoc. Petrol. Tech., 62, 59-69, 1997 (in Japanese with English abstract).

Yanagisawa, Y., I. Kobayashi, K. Takeuchi, M. Tateishi, K. Chihara, and H. Kato Geological Sheet Map 1:50,000 "Ojiya", Geological Survey of Japan, 1986.

M. Uyeshima (e-mail: uyeshima@eri.u-tokyo.ac.jp), Y. Ogawa, Y. Honkura, S. Koyama, N. Ujihara, T. Mogi, Y. Yamaya, Makoto. Harada, S. Yamaguchi, I. Shiozaki, T. Noguchi, Y. Kuwaba, Y. Tanaka, Y. Mochido, N. Manabe, M. Nishihara, M. Saka, and M. Serizawa 